\title{
Moving Forward to New Trends in Liver Transplantation
}

\author{
Alessandro Parente ${ }^{1,2, *(D)}$ and Vincenzo Ronca ${ }^{2,3}$ (D) \\ 1 Department of Hepatobiliary Surgery and Transplant Unit, Tor Vergata Hospital, Tor Vergata University of \\ Rome, 81, Viale Oxford, 00133 Rome, Italy \\ 2 Liver Unit, Queen Elizabeth Hospital Birmingham, Birmingham B15 2TH, UK; v.ronca@bham.ac.uk \\ 3 Centre for Liver and Gastrointestinal Research, Institute of Immunology and Immunotherapy, University of \\ Birmingham, Birmingham B15 2TT, UK \\ * Correspondence: aleparen@gmail.com
}

Citation: Parente, A.; Ronca, V. Moving Forward to New Trends in Liver Transplantation. Transplantology 2021, 2, 294-295. https://doi.org/ $10.3390 /$ transplantology2030029

Received: 3 August 2021

Accepted: 9 August 2021

Published: 18 August 2021

Publisher's Note: MDPI stays neutral with regard to jurisdictional claims in published maps and institutional affiliations.

Copyright: (c) 2021 by the authors. Licensee MDPI, Basel, Switzerland. This article is an open access article distributed under the terms and conditions of the Creative Commons Attribution (CC BY) license (https:// creativecommons.org/licenses/by/ $4.0 /)$.
Liver transplantation (LT) is the only recognized effective treatment for end-stage liver disease (ESLD) and acute fulminant liver failure. Nowadays, a good survival of $>90 \%$ and $>75 \%$ at one year and five years, respectively, can be achieved.

However, despite recent improvements in donor and recipient selection, perioperative management and organ preservation techniques, there are still several challenges that the transplant community has to face.

The disparity between available liver grafts and waiting list candidates is still elevated and patient mortality whilst awaiting is as high as $10 \%$ yearly. In this setting, changing trends in characteristics of patients listed for LT are of great interest as they can impact the decision-making process for recipient selection. In former times, hepatitis $C$ virus (HCV)-related cirrhosis was the main indication for LT. With the recent introduction of a direct-acting antiviral agent for $\mathrm{HCV}$, it is expected that the frequency of LT performed for this condition will decline and, in the near future, it could become an uncommon cause of ESLD. Furthermore, in the Western countries, the continuously increased rates of alcohol intake, diabetes, hypertension and obesity, as well as sedentary lifestyle changes, will raise the incidence of non-alcoholic steatohepatitis (NAFLD), which can lead to ESLD. There is evidence that NAFLD, together with alcoholic-related liver disease, could soon become the leading indication for LT [1]. As a results, there will be an increasing need for liver grafts. On top of this, the recent advances in transplant oncology showed that LT can be an effective treatment for other types of primary and secondary liver cancers beyond hepatocellular carcinoma. These types of evidence could change the trends in indication for LT [2].

In the last decades, rates of organ donation have been promisingly increasing. In addition, utilization of marginal grafts, donation after cardiac death (DCD) and novel preservation techniques have been pursued in order to expand donor pool donor. However, donor suitability has decreased and many liver grafts are still discarded [3]. This is mainly attributed to the poor quality of liver grafts, related to the older age of the donors who might have additional multiple comorbidities. In this regard, organ reconditioning and novel preservation techniques, such as machine perfusion and viability assessment, could be a compelling solution to rescue suboptimal grafts and increase the donor pool. Additionally, recent advantages of perioperative care have led to improvements in live donor liver transplantation, which has been successfully used to expand organ availability and decrease the mortality on the waitlist.

Looking to the future, the transplant community will need to maximize organ utilization and revise allocation systems to decrease waiting list mortality whilst maintaining the current excellent outcomes of transplantation.

All studies discussing these challenges that are changing liver transplantation activity are welcomed to the current Special Issue entitled "Liver Transplantation: Current Status 
and Future Challenges" to analyze and debate possible solutions, shaping the future of liver transplant practice.

Funding: No funding to declare.

Institutional Review Board Statement: Not applicable.

Informed Consent Statement: Not applicable.

Data Availability Statement: Not applicable.

Conflicts of Interest: The authors declare no conflict of interest.

\section{References}

1. Yi, Z.; Mayorga, M.E.; Orman, E.S.; Wheeler, S.B.; Hayashi, P.H.; Barritt, A.S., 4th. Trends in Characteristics of Patients Listed for Liver Transplantation Will Lead to Higher Rates of Waitlist Removal Due to Clinical Deterioration. Transplantation 2017, 101, 2368-2374. [CrossRef] [PubMed]

2. Manzia, T.M.; Parente, A.; Angelico, R.; Gazia, C.; Tisone, G. The Revolution in Indication for Liver Transplantation: Will Liver Metastatic Disease Overcome the End-Stage Liver Disease in the Next Future? Transplantology 2020, 1, 111-122. [CrossRef]

3. Orman, E.S.; Mayorga, M.E.; Wheeler, S.B.; Townsley, R.M.; Toro-Diaz, H.H.; Hayashi, P.H.; Barritt, A.S., 4th. Declining liver graft quality threatens the future of liver transplantation in the United States. Liver Transpl. 2015, 21, 1040-1050. [CrossRef] [PubMed] 